\title{
Ambivalence in International Dialogue: Implications for Diplomatic Training
}

\footnotetext{
Keywords:

diplomat

ambivalence

emotions

negotiations

conflict

culture

competence

training
} 


\begin{abstract}
Diplomats are civil servants who represent their governments abroad. By the nature of their work, diplomats work in multicultural environments. Working in intercultural settings can involve grey areas, paradoxes, and a wide range of emotions. This article analyzes how diplomats construct their professional identity, how they approach intercultural diversity and how they manage ambivalence. Qualitative interviews with senior diplomats as well as a review of literature from multiple disciplines indicate that it is vital for diplomats to be highly skilled in self-management; in building and maintaining relationships; and in operating in intercultural environments. We argue that it is essential to include these emotional, social, and cultural competences in diplomatic training so that diplomats may become effective bridge-builders. This will be particularly relevant for a diplomat whose country is currently involved in a conflict with another country, as well as for diplomats who work in the context of a political conflict.
\end{abstract}




\section{Introduction}

Diplomats play an important role in representing their countries abroad, forging relationships and working toward a peaceful world. By definition, diplomacy takes place across borders and involves contact with representatives of different backgrounds. Working in intercultural settings can involve grey areas, paradoxes, and a wide range of emotions; these maybe amplified by past or on-going conflict situations (see, for example, Barna, 2009, and Maalouf, 2002).

In this article, we want to explore to what extent diplomats experience ambivalence in their work and how they cope with conflicting and unsettling emotions. ${ }^{1}$ Diplomats are under the spotlight at all times and have to avoid any behavior that may reflect negatively on them or their country and/or damage their relations with their host country counterparts and other members of the diplomatic corps. In particular, we are interested in understanding how a political conflict situation impacts the identity of diplomats and their behavior and performance. How do diplomats manage ambivalence at the intersection of their personal and professional identities? And how does ambivalence inflicted by differing cultural contexts impact on a diplomat's work and self-understanding?

Our interest in this topic was spurred by a training course on intercultural communication that we held at ADA University (formerly: Azerbaijan Diplomatic Academy or ADA) in Baku, Azerbaijan, in May 2014. "Dealing with difficult emotions" was one of the issues that junior diplomats identified as a key challenge in their work. We found this issue compelling and set out to learn more about the topic with the objective of informing diplomatic training efforts.

For the purpose of this article, ambivalence is defined as inconsistency within or between the components of an attitude. In other words, the object of the attitude is simultaneously regarded positively and negatively (Thompson, Zanna, \& Griffin, 1995). According to Eagly and Chaikin (1993), people respond to others by making evaluations, expressing feelings and cognitively processing aspects of the object. In general, ambivalent attitudes are less predictive of particular behaviors than are non-ambivalent attitudes (Armitage \& Conner, 2000). Feeling ambivalent about a situation also tends to make an individual less likely to take action. Lavine, Huff, Wagner, and Sweaney (1998) showed that when attitudes were high in affective-cognitive ambivalence, the affective component affected the behavior more than the cognitive component. We suggest that ambivalence is a significant factor affecting diplomats' behavior since they are expected to "be diplomatic" and maintain composure while managing ambivalence at different levels and working in cultural contexts different from their own.

Ambiguity and ambivalence are present in every human psychological act (Abbey \& Valsiner, 2004, 2005). We approach our research question through a discussion of the identity formation of diplomats and their approaches to cultural diversity. We have explored the topic empirically through qualitative interviews with seven diplomats who (i) are from countries currently involved in unresolved conflict situations; and/or (ii) have worked in countries with on-going conflicts. We were particularly interested in critical incidents that shaped a diplomat's belief system and intercultural understanding. In our research, we do not cover the political, historical and social contexts of conflicts. We recognize that conflicts

1 This article was first presented at the Annual Conference of the Norwegian Association of Intercultural Competence (NOFIK) in Oslo (16-17 October 2014) and at the $6^{\text {th }}$ Black Sea International Symposium held at Giresun University, Turkey (6-8 November 2014). It was accepted by FLEKS in April 2015 and revised in May 2015. 
are complex, but our main purpose here is to better understand how ambivalence can impact diplomats and what coping behaviors diplomats use.

This article provides input for the development of training programs for junior diplomats to (i) better understand and manage their emotions; (ii) comprehend others' emotions and develop resonant relationships with other diplomats in a constructive manner without betraying their sense of national loyalty; and (iii) perform effectively across cultures. We hope that the findings of this article will be useful to policy-makers, curriculum developers and trainers at diplomatic academies and other relevant educational institutes to fine-tune competence-based diplomatic training. We also hope to contribute to the important discussion on the human factorin international diplomacy and negotiations (Rifkind \& Picco, 2014; Sirin, Villalobos, \& Geva, 2011).

\subsection{Setting the Context: Diplomatic Culture and Identity}

Diplomats are official representatives of sovereign states and their governments. The word "diplomat" appeared for the first time in the $19^{\text {th }}$ century in French (diplomate). It stems from the Greek word diploun (to fold) and diploma (folded paper), which in the mid-17 ${ }^{\text {th }}$ century took on the meaning of state paper (Oxford Dictionary). As envoys of their governments, diplomats have conveyed messages between countries for hundreds of years. Some of the earliest artifacts proving diplomatic relations between ancient empires go back as far as the second millennium BC, such as the Amarna tablets found in Egypt (Kappeler, 2004). Abba Eban notes that the word "messenger" has both sacred and secular meanings in Greek (angelos) and Hebrew (mal'ach; as cited in Sharp, 1997, p. 615).

The academic discourse around diplomacy and diplomatic culture has focused on five elements: ceremony, symbolism, interests of their sovereign, power, and ideas, such as the promotion of peace (Sharp, 1997). Culture is widely understood as "the collective programming of the mind" of individuals belonging to a group (Hofstede, 2004, p. 26). The professional culture of diplomacy is visible through a number of artifacts: for example, diplomats use certain proceedings in their work (protocol) and they are protected by a number of privileges set out in the Vienna Declaration on Diplomatic Relations (1961). There is also a clear hierarchy within the diplomatic corps, expressed among other things by the universally agreed use of titles and ranks as well as the prescribed seating order at diplomatic functions.

The values underlying diplomatic culture are more difficult to assess. Diplomacy does not occur in a vacuum, but is guided by the interests and the relative power of countries. Diplomatic culture is also not static, having adapted over time to changing needs and circumstances (Rana, 2004). Universal diplomatic culture rests on two pillars: international law and a shared cultural mode. Pasquali (2014) has raised important questions regarding the existence of a universal diplomatic culture. He argues that "[...] no moral standard of diplomacy is universally identifiable, and that although different cultural approaches coexist, these are often supported from the egoistic standpoint of self-interest" (pp. 278-279). Rana (2004) notes that "[c]ommonalities among all diplomatic establishments persist, but are less of a unifying force than before" (p. 389).

Our objective in this paper is not to discuss the existence and manifestations of diplomatic culture at the collective level, but to look at the individual level. We hope to contribute to a better understanding of the human side of diplomatic work: the emotions and capacities involved - an aspect that is often neglected or overlooked. Russell (2004) discussed the possibility of diplomacy having a global emotion culture, i.e. "an international professional standard of emotional behavior". She suggests that there may be an established way of 
experiencing and expressing emotions in diplomacy, which is acquired by individuals during their socialization as diplomats (p. 398). Our objective with this paper is not to look at the level of culture and rules, but to look at personal experiences "beyond the structures of faceless bureaucracies that create circuses of diplomats" (Rifkind and Picco, 2014, p. Xx). The Swiss diplomat Heidi Tagliavini (2013), for example, described her experiences as a diplomat in crisis situations as follows (p. 27):

[W] hat matters, especially in such delicate environments as in a conflict is in fact something very different than just your professional capacities. It is all about values and personal skills.

There has been a strong focus on the cognitive abilities of diplomats. Analyzing writings by diplomats, Sharp (1997) notes that "they present themselves as practical men and women who take the world for what it is, rather than what it might be, and who let reason, rather than emotion, govern their actions" (p. 626). But who are the human beings behind these rational diplomats? What are the elements of their identities, and to what extent are these elements fluid?

As a personal meaning system, identity shapes an individual's self-understanding and provides a sense of belonging and guidance. A person's identity consists of different elements or affiliations, such as language, nationality, gender, religion and profession. Depending on the context, and also throughout a person's lifetime, the hierarchy and combination of affiliations may change (Maalouf, 2002). Nor is identity a singular construct: in fact, it is made up of different affiliations of the kind described above or, in other words, of plural identities that co-exist. The Norwegian diplomat Knut Vollebæk, former Norwegian foreign minister and OSCE High Commissioner on National Minorities, responded to a question on diversity and minorities by noting: "Most of us will have many identities at the same time" (Froese, 2013, p. 36).

The professional identity is part of the overall identity, or self-identity, of a diplomat. It is constructed as the result of the individual's decision to enter diplomatic service. ${ }^{2}$ Diplomats become members of their country's foreign service; at the same time, they become part of the global diplomatic corps. Together with other allegiances, their professional identity will contribute to their overall self-identity. Depending on the situation and/or the diplomat's choice, one or more allegiances might be predominant. The following table summarizes the analytical framework that we have devised for our research to track the affiliations influencing a diplomat's self-identity:

2 Unless a diplomat grew up in a diplomatic family, which was common for most diplomats until the mid$20^{\text {th }}$ century. 


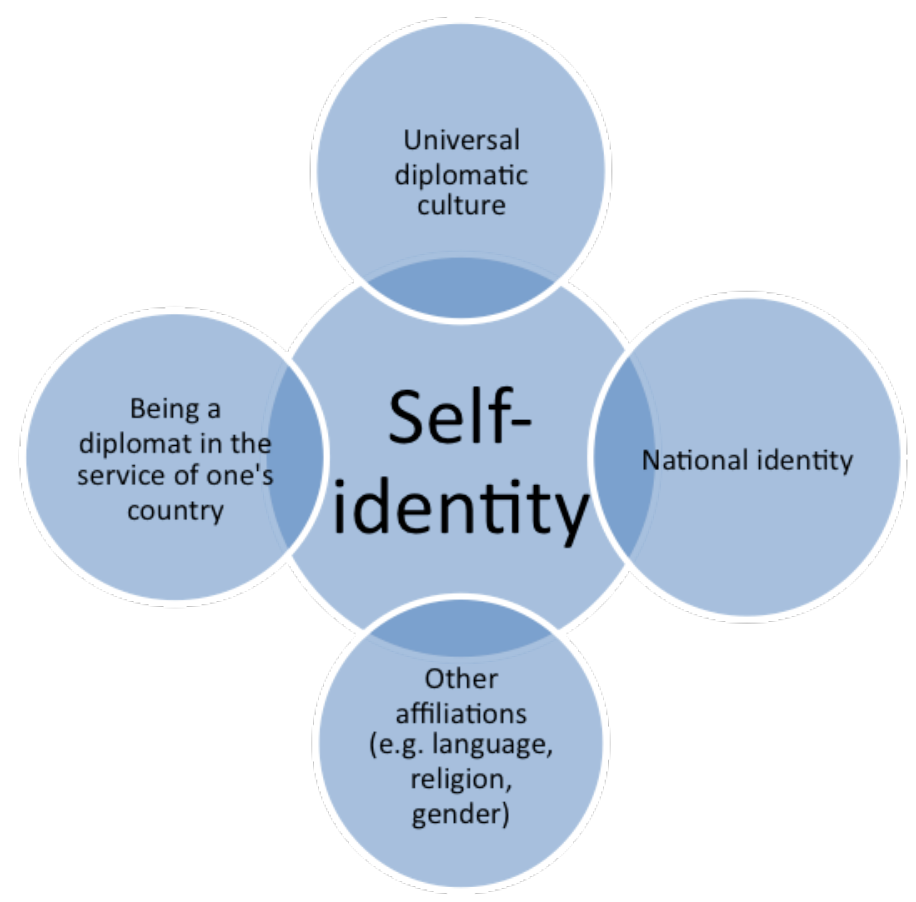

Figure 1: Analytical framework for a diplomat's self-identity

(Schnitzer-Skjønsberg and Mustafayeva, 2015)

Rifkind and Picco (2014) note that conflict situations can lead to a questioning of identities. Maalouf (2002) points out that "people often see themselves in terms of whichever one of their allegiances is under attack" (p. 26). This is why the national identity tends to have a stronger pull in times of conflict. The capacity to humanize the other side decreases, both at individual and group level, as a conflict emerges. Diplomats from a country that is party to a conflict may find themselves trapped in a newly emerged national identity. Dehumanizing the other side might in fact be the expected narrative. Their role may require them to hate and show their discontent and anger strongly given their public profiles. To reduce tension and contribute to conflict resolution, diplomats have to lift themselves above the expected national narrative without compromising their tasks as representatives of their government.

The ability to foster high-quality professional relationships over time is indispensable for a diplomat in order to strengthen cooperation and to reduce tension at the bilateral level and in multilateral fora. William Luers, a former U.S. career diplomat and U.S. ambassador to Czechoslovakia and Venezuela, noted the fundamental importance of knowing "how to deal with adversaries [...] how to position oneself psychologically ... and understand what they want, knowing what you want" (as quoted in Rozen, 2014). In the face of ambivalence and conflicting identities, this can be a daunting task for any individual. This is why it is critical for diplomats to find effective strategies to cope with ambivalence and competing demands on their professional and individual identities. We want to explore what coping mechanisms experienced diplomats have established for themselves. 


\subsection{Our Research}

This article is based on explorative qualitative research. From July to September 2014, we conducted semi-structured interviews with senior diplomats from Austria, Israel, Morocco, Norway, Pakistan, the State of Palestine, and the United States of America $(\mathrm{N}=7) .{ }^{3}$ We were particularly interested in learning about any critical incidents the informants had been involved in. Notwithstanding the limited sample size, patterns emerge from the interviews that we feel are worth reporting and which may guide further research.

The four main principles of the Code of Human Research Ethics by the British Psychological Society (2010; respect for the autonomy and dignity of persons; scientific value; social responsibility; and maximizing benefit and minimizing harm) guided our research. Participants were selected from the pool of diplomats that we had access to through our professional networks. Since the aim of the research was to bring the experience of seasoned diplomats into the training of junior diplomats, we only contacted diplomats with at least 20 years of experience of diplomatic service. We did not approach diplomats working for multilateral organizations, since international public servants are required to act on behalf of the organizations they represent and not their country of origin.

All participants received a standard e-mail describing (i) the purpose of the research, (ii) the topic of the interview, illustrated by some sample questions, and (iii) possible outcomes of the research (i.e. an academic publication and a resource for diplomatic training). Some of the participants were approached in person before being sent the e-mail. All e-mails included a confidentiality statement. Participants confirmed their consent to participate in the research by replying positively to the e-mails. Interviews were held in English and conducted at the time and place most convenient for the interviewee. In cases where a face-to-face meeting was not possible, interviews were conducted via Skype.

Special attention has been devoted to omitting identifying information when choosing quotes and examples. Excerpts from the interviews are thus not linked to the nationality of the respective informants. This also helps to avoid any national stereotyping. Some of the interviewees had served in Azerbaijan at some point in their careers, but not all of them. Six of the interviewees were men; one was a woman. While increasing numbers of women are taking up important diplomatic posts, women are still outnumbered by men at the senior level. The gender imbalance in our sample reflects this situation.

\section{Literature Review}

We decided to review the literature on negotiation and leadership to guide our research on identity and conflict, as well as on the role of self-management, relationship building, and intercultural effectiveness. We were particularly interested in attributes that make leaders effective across cultures. Our goal is to identify the key competencies of effective leaders and transfer those competencies into diplomatic training and, for the future, to develop learning activities and tools that will reinforce those competencies in serving diplomats.

We understand a competency as "a capability or ability that leads to or causes effective performance" (Emmerling \& Boyatzis, 2012, p. 7, see also Boyatzis, 2008, McClelland, 1973). Competencies are also described as clusters of abilities or skills mobilized around an intent (Boyatzis, 2008). The intent prompts action(s). The choice of action(s) will depend on the individual's cognitive, emotional, social and cultural intelligence, which will predict the individual's behavior and effectiveness in a situation. According to Boyatzis (2009), each competency is comprised of three threshold clusters: expertise and experience; knowledge;

3 We follow the designations used by the United Nations. 
and the assortment of basic cognitive competencies such as memory and deductive reasoning. The term competence-based evaluation was first introduced by McClelland in 1973 to measure the effectiveness of different professions. Boyatzis (2008) claims that emotional and social intelligence competencies play a substantial role in predicting or understanding performance.

Initial research on negotiator performance focused on the cognitive, decision-making aspect of negotiations (see, for a discussion, Bazerman, Curhan, \& Moore, 2000). This approach minimized the importance of the individual characteristics of the negotiator and put more emphasis on situational determinants of negotiator behavior. Researchers came to the conclusion that given the same situation or context, most negotiators will behave similarly and will make similar mistakes. Most of the research supporting the idea that "no matter who negotiates there are only limited choices of actions within the confines of bounded rationality" has focused on the simple experimental bargaining paradigm (see, for example, Rubin \& Brown, 1975). For distributive negotiations, when the parties are dividing a fixed pie, this still holds true: the individual aptitudes of the negotiator make very little or no difference.

However, expectations of negotiations have changed since then. A good negotiator has to use a more integrative approach to negotiations, taking the complexity of the context and situation into account. In other words, the game has changed: it is about expanding the pie, meeting all parties' interests and expectations. In this context, the individual characteristics of the negotiator become more salient. Research shows that cognitive abilities of individuals, such as information acquisition and processing, decision-making and learning, have a bigger impact on performance as situations become more complex (LePine, Colquitt, \& Erez, 2000). In their 1998 study on cognitive intelligence and negotiation outcomes, Barry and Friedman found that the combined cognitive ability of negotiation dyads, as measured by the sum of their admission test scores, was strongly related to ratings of the outcome integrativeness. The higher the score, the more integrativeness the dyad displayed. This tells us that the cognitive ability of diplomats plays a certain role in their effectiveness.

Cognitive ability, however, is not the only determinant of an individual's performance. Research shows that emotional intelligence plays as important a role in social interactions, if not more (Goleman, 1995, 2006). Having first introduced the term in 1990, Mayer and Salovey (1997) define emotional intelligence as the ability to both perceive and express emotions, the ability to access emotions in facilitating thought, the ability to understand and analyze emotions, and the ability to regulate emotions in the self and others. Goleman (1995) identified the following five sub-constructs of emotional intelligence: self-awareness, self-regulation, motivation, empathy, and social skills. Both definitions highlight the importance of knowing oneself and being able to manage oneself. Bar-On (1997) found that emotional intelligence can help people cope successfully with environmental demands and pressures. This is why people who are better able to control or redirect their disruptive impulses and moods feel more comfortable with ambiguity and are more open to change. In addition, individuals with high emotional intelligence are better at managing relationships and building networks, and more able to find common ground and build rapport (Goleman, 1995).

Leadership research has shown that the emotional intelligence of leaders increases the effectiveness of organizations. Recent research indicates that these findings hold true across different sectors and also across different countries (Emmerling \& Boyatzis, 2012). Advances in social neuroscience have helped us to better understand the effects of emotions on our brains, bodies and ultimately on our behavior. We know, for example, that when a person experiences a negative emotion, the parasympathetic nervous system is activated 
and stress levels increase. As a result, the individual will experience reduced cognitive abilities and will be less open to new experiences. It is obvious that such a state is highly undesirable for a diplomat. We also know that emotions are contagious, whether they are positive or negative. Moreover, scientists estimate that it takes three positive experiences to counteract one experience invoking negative feelings (Boyatzis, 2011). While negative emotions and anger in particular are critical for saving us from harm by inducing us to change ourselves or change the conditions around us (Kastner, 2014), it is positive emotions that lay the basis for the resonant relationships that need to be fostered by diplomats.

The good news is that emotional intelligence can be developed and nurtured through training at all ages. Researchers at Case Western University have shown that including modules on emotional intelligence in classes for MBA students significantly improved their emotional and social competencies (Boyatzis, 2009). In order to invoke a behavior change, it is important that individuals find themselves in a state of positive emotional arousal. Mastracci, Newman, and Guy (2010) make the case for including emotional labor work in the curricula for students of public administration in order to provide better services for citizens upon graduation. They urge us to "[T]hink of emotion work as the art of public service, while the exercise of cognitive skills represents the science of public service" ( $p$. 137). To be an effective public servant, the mastery of emotion work and cognitive skills is vital.

The latest research on social neuroscience has also pushed the work on social intelligence forward. Social intelligence can be defined as a set of interpersonal competencies built on specific neural circuits and related endocrine systems that inspire others to be effective (Goleman, 2006). Social intelligence is not a new term; it has been well researched and documented by researchers going back to 1920 when E. L. Thorndike identified it as "the ability [...] to act wisely in human relations" (p. 228). Albrecht (2006) designed a framework for understanding social intelligence. It is based on the following five competencies: situational awareness, presence, authenticity, clarity, and empathy.

Albrecht (2006) has also drawn our attention to the critical role of context in social interactions: "When we understand that there can be no human interaction without a context in which it takes place, we begin to understand how context creates meaning and how the meaning supplied by the context shapes the behavior of those who are engaged in it" (p. 2). This highlights the importance of diplomats' ability to observe and understand the context they are working in - a context that is often also culturally very different from the one they are representing. Märtsin and Mahmoud (2012), for example, note that "[...] the experience of moving away from home activates the dialectic of home and non-home, as these become simultaneously present and absent in our way of being in a new context" ( $p$. 736).

In today's interconnected world, working in multicultural environments has become the norm rather than the exception. Diplomats, by the nature of their work, do not only work with people of diverse cultural backgrounds but they also perform their duties in different cultural contexts. The psychologists Eysenck and Eysenck (1995) note that "[0]ur differences make living together extremely difficult, whether in a family, state or international context' (p. 212). Understanding and acknowledging these differences is the first step in becoming more effective in coping with them. Cultural intelligence has been defined as an individual's "capability to adapt effectively to new cultural contexts" (Early \& Ang, 2003, p. 59). Van Dyne, Ang, and Koh (2009) have defined four factors of cultural intelligence (CQ): (i) an individual's consciousness and awareness during cross-cultural interactions (metacognitive CQ), (ii) an individual's cultural knowledge of norms, practices 
and conventions in different cultural settings (cognitive CQ), (iii) an individual's capability to direct attention and energy toward cultural differences (motivational CQ), and (iv) an individual's capability to exhibit appropriate verbal and non-verbal actions when interacting with people from different cultural backgrounds (behavioral CQ).

Cultural intelligence is not competing with the other forms of intelligence (cognitive, social, emotional). On the contrary, it is another gem in the beautiful kaleidoscope of the human mind or what is traditionally called "multiple intelligences" (Elenkov \& Pimentel, 2008). Some scholars view it as an extension of emotional intelligence (Van Dyne, Ang, \& Livermore, 2010), while others claim that the different forms of intelligence co-exist in the human mind, and the situational context will test them. A study of 126 Swiss military officers showed that cultural intelligence was a stronger predictor of cross-border leadership effectiveness than emotional intelligence (Rockstuhl et al., 2011). However, for leadership effectiveness in domestic assignments, emotional intelligence was a stronger predictor than cultural intelligence. As for general intelligence, the researchers could find no difference: it predicted both domestic and cross-border leadership effectiveness.

But what exactly constitutes intercultural competence? A review of the status of conceptualizations of intercultural competence revealed that more than 300 concept and factor labels have been identified (Spitzberg \& Changnon, 2009). According to Deardorff (2009), the desired outcome of intercultural competence is "effective and appropriate behavior and communication in intercultural situations" (p. 479). She describes intercultural competence as the process of developing and nurturing attitudes, knowledge and skills that can manifest themselves in internal outcomes (e.g. flexibility, adaptability, and empathy) leading to the overall external outcome. In the same vein, Van Dyne et al. (2010) caution that focusing on one factor of cultural intelligence may "result in increased cultural ignorance rather than resulting in enhanced cultural intelligence" (p. 3). In other words, they argue for a more holistic approach to the development of cultural intelligence. The challenge will be to integrate and further test existing concepts to distill the most critical factors and develop manageable training tools.

Traditional diplomatic training for junior diplomats tends to put the emphasis on cognitive intelligence as the quality measure for an effective diplomat. Most diplomats are wired to work on their analytical skills, such as information finding and processing, pattern recognition and self-learning. Growing research shows, though, that cognitive abilities are poor predictors of leadership effectiveness. Judge and Piccolo (2004) examined the relationship between intelligence and leadership effectiveness by a meta-analysis of 151 empirical studies. They came to the conclusion that the relationship between intelligence and leadership effectiveness is lower than previously assumed. Senior diplomats interviewed for this study also very rarely mentioned cognitive abilities as a predictor of the effectiveness of a diplomat. However, attributes such as self-awareness and selfmanagement, the ability to listen, empathy, respect for other people and cultures, genuine interest in other cultures and people, the ability to build relations, and flexibility were mentioned again and again. This tells us that it is time to focus on the "neglected three" in diplomatic training: emotional, social, and cultural intelligence.

We believe that tailored competence-based training programs can help boost a diplomat's performance in all these three areas. Others have also called for competence-based human resource management in foreign service. In the mid-1970s, the U.S. State Department 
commissioned a study on competency requirements of senior and mid-level diplomats. ${ }^{4,5}$ More recently, Megahed and colleagues (2012) have made the case for the development of a multiple-jobs competency model for the diplomatic profession and devised a model for the Bahraini and Egyptian Ministriesof Foreign Affairs. We hope that our findings stemming from the interviews conducted with senior diplomats will allow us to better understand the set of competencies reflecting critical emotional, social, and cultural intelligence competencies that diplomatic training should embody.

\section{Findings}

Our interviews were designed around two factors that may lead to ambivalence in diplomatic work: (i) the interplay of professional and national identities; and (ii) the experience of cultural diversity. The findings of our research indicate that the underlying competencies are universal across countries.

\subsection{Ambivalence and the Interplay of Professional and Personal Identities}

We found that the diplomats displayed a highly developed sense of professional identity. They perceived their identity as diplomats as distinct from their personal identity. At the same time, they acknowledged that their personal identity influenced their identity as a diplomat. All interviewees stressed the inherent professionalism required by their jobs.

A diplomat's job is to represent their government's interests, to build bridges and to strengthen relationships between the home country and the host country. In the words of one diplomat: "Diplomats are not soldiers, they are peace builders. We are not there to fight with one another; we are there to build bridges." Another diplomat noted: "[...] you have to keep your emotions out, that's being professional." Diplomats seem to be obliged to manage their negative emotions, such as frustration and anger, so that they do not impact their work. One interviewee mentioned that they were expected to conceal negative emotions. The display of positive emotions such as empathy and gratefulness, on the other hand, is encouraged.

A central element of the professional identity, highlighted by most interviewees, was the acknowledgement that the world was complex. One diplomat noted: "By nature, diplomats have to be comfortable with a lot of ambiguity". In the words of another diplomat: "I come with an open mind, I keep reminding myself that the world is not the way I see it. I observe and learn." This indicates a high sense of self-awareness in experienced diplomats. Effective communication is crucial for understanding the other party. Indeed, interviewees highlighted the importance of being good listeners. One diplomat put it like this: "We should listen to find out how the other party builds their arguments, learn what we do not know, before we open our mouth." There are also many ways to convey messages, one diplomat noted:

\footnotetext{
4 "Competency requirements of senior and mid-level positions in the Department of State", Final Report. Prepared by David D. McClelland, George Klemp, Jr., and David Miron, McBer and Company Boston, June 1,1977 . The five competencies identified were specialized knowledge, leadership skills, intellectual skills, managerial skills and interpersonal skills.

5 Boyatzis was also involved in the study for the U.S. State Department in 1977 (personal communication, 15 December 2014).
} 
Know who to speak to, where to speak, and how to speak. A diplomat does not have to speak at every occasion; we are not actors or speakers. We should choose carefully where we speak and when we listen. And if we decide to speak, we should be short and concise.

Ambivalence is part of the daily life of professional diplomats. The level of dissonance will vary with the context and the degree of seniority. Our interview partners stressed the need to clearly distinguish the personal from the professional even if they are strongly linked. As representatives of their governments, diplomats are "just doing their job". This basic differentiation enables a diplomat to build the relationship with another diplomat both at the professional and personal level. "Both people understand they speak to each other as diplomats, this is reassuring", noted one diplomat.

There is a lot of ambivalence in our job. I deal with ambivalence directly. Whenever I feel like a fellow diplomat hints something related to [my country] or our foreign policy priorities, I try to understand, and if I am not sure, I just ask directly and check my understanding. People appreciate honesty and sincerity.

The diplomats we spoke to emphasized that the way one thinks might be very different from the way that the other party thinks - that, in fact, the extent of how differently we think is often largely underestimated. Dealing with ambivalence thus calls for trying to understand the motives, the motivation and the way of thinking of one's counterpart. A diplomat must have a sincere desire to understand the other side. One diplomat used the following analogy:

If we compare diplomacy to swimming, you need to know your pool - the depth, the length - when you get in, but you should also mentally be prepared for ambivalence, and have that strength to swim the extra mile or two.

Although diplomats mentioned that "being professional means leaving your emotions out", they are experiencing emotions. One diplomat acknowledged that "you will be gripped by your emotions in many of these situations [i.e. tense international negotiations]". Another diplomat recounted a moment when another diplomat attacked his country in a sharp comment. He remained calm, although he asked himself later whether he should have responded more harshly to defend his country.

A political conflict situation can impact the professional identity of a diplomat via the national narrative and/or being part of a highly charged situation. The diplomats we interviewed seemed to make the conscious choice to lift themselves above difficult emotional states. The following statement illustrates how one diplomat approaches speaking to colleagues from a country his government is in conflict with:

I consciously focus on apolitical topics to build a human rapport. I know that I am not decision-maker, neither is he. I try to get to know him as a human being. I talk about everyday issues, about preferences. You need to create a rapport that is out of the context of the conflict. Can we connect on a human level? Can he see me, can I see him? Human decency is common, shared values are common. We all want peace, don't we? 
If difficult emotions, such as anger, arise, they cannot be ignored but need to be dealt with responsibly (Kastner, 2014). We found that diplomats have developed specific coping mechanisms. One of them is to humanize the other and "force yourself to look at different angles of the story". A critical aspect of this is to differentiate between the political/professional level and the personal level. Another interviewee has developed a personal technique to help him move beyond a negative state: "When I feel such emotions kicking in, I check in with myself and do a certain body move." Through this personal ritual, the diplomat is able to feel the emotion, acknowledge its temporary presence and then rise above it constructively - instead of entering into a negative and potentially unconstructive mode (on modes, see for example, Bennett-Goleman, 2013).

Diplomats may also experience deliberate provocations in their work, going beyond constructive criticism. One interview partner noted that a provocation may indicate that the other side knows that your side has better arguments. It is important not to get into a process of tit-for-tat, but to find better approaches. "Like a chess player, look for alternative routes" was the advice of one diplomat. Another diplomat said that it was more productive to absorb the provocation, to calm down and to respond assertively, but without agitation. In the end, diplomats invest in relationships for the long-term. One diplomat described a serious diplomatic crisis that was successfully solved partly because of the relationships among diplomats of both countries that had been fostered long before the crisis broke out.

\subsection{Ambivalence and Cultural Diversity}

Due to the nature of their profession, working with people from different cultural backgrounds is a diplomat's daily bread. This makes coping with cultural diversity a key competence for any diplomat. Bolewski (2008) also notes that "[i]n practice, diplomacy is as much about cultural relations as it is about political relations" (p. 155). The diplomats interviewed emphasized the importance of educating oneself when starting a new posting abroad. The diplomats said it was critical to read as much and as broadly as possible. Poetry and novels, for example, can provide a deep insight into a country's value system. The diplomats also suggested that it was useful to talk to people who had lived in the country before.

At the same time, it is helpful to start a new posting with a fresh mind and learn through personal experiences. One diplomat put it like this: "You refocus so much at all levels [when you begin a new posting]. You do a lot of observation, you go back to default." In this process, an important element for successful interaction with representatives of other cultural backgrounds is a deep sense of curiosity. One interviewee has developed the following approach:

Genuine interest and curiosity lay the basis for a diplomat's successful posting abroad. [...] Interaction with locals is vital. Being accessible and approachable will support a smooth transition into a new culture. A hobby can be an excellent way to get to know locals and also other non-diplomat expats; it allows a diplomat to expand his or her horizon and explore levels of society that might have otherwise been out of reach.

Another diplomat also emphasized the importance of getting to know the local culture and representatives from the host country. The diplomat put it like this: "[T]o the extent possible, I follow the lead of the locals whenever it comes to the cultural ambivalence." In order to establish contacts, this is what he does: 
I go out and meet locals almost every day, I speak to my neighbors, I know their names, where they work, I invite them over when I can. I travel to the regions, get to know local people, chat with them whenever possible. I know the best local restaurants. Locals get surprised when they hear that I have been to these restaurants.

Understanding the cultural context enables the diplomat to do a better job. "As the cultural setting changes the rules of the game also change", emphasized one diplomat. Diplomats need to respect the local chain of command and the culturally appropriate way of communicating. For example, countries can differ greatly in their attitudes towards hierarchy (Hofstede, 2004). Once the diplomat understands the country's values on this, they will be able to better interpret events and strategize actions more effectively. If a diplomat works in a country characterized by a high power distance (Hofstede, 2004), it will be important to seek meetings at the highest levels possible. Meetings with junior colleagues, even if they might be more knowledgeable about the topic, will not be fruitful for further cooperation.

Another example is the value of fostering personal relationships in high-context cultures (Hall, 1976, Korshuk, 2004). For example, the diplomat will carefully observe the context in which meetings take place: who attends meetings, at what levels, where does a dinner take place. All these subtle clues are meaningful: it is the diplomat's job to join the dots and understand the signals conveyed.

If there was one sentiment that emerged from all interviews, it was the importance of showing respect: for your interlocutors, for the country, and for the culture. One diplomat emphasized that respect has to be genuine because "people will feel if you put on a show". Respect also extends to potential language barriers. English has become the lingua franca among the diplomatic corps in many countries and also for interactions with local partners. If a counterpart does not speak good English, he or she may be easily dismissed by others. This maybe a mistake, both at the human and strategic level, as the following account shows:

Never look down on somebody who does not speak English well. There is a proneness to do this and to belittle the other person, which is a sign of disrespect. One ambassador did not speak much English, and it took time to establish contact with him. Many might have disregarded him as a partner. But speaking to him, even if I only understood $50 \%$ language-wise, helped me more than speaking with other diplomats who spoke fluent English. He was extremely resourceful.

There was general agreement that it helps considerably if you speak the local language, or at least one of the local languages if there are more than one. At a minimum, one should learn how to greet a person in the local language. One diplomat highlighted that body language tends to be underestimated. For example, countries have their own specific ways of greeting. If one observes, learns and applies them, one will be able to greet counterparts accordingly. This might seem like a small detail, but using the local form of greeting conveys respect and will help establish trust. If a diplomat is involved as a mediator in conflict resolution, this gesture may in fact make a significant difference in the way the mediator will be perceived by the parties to the conflict, at least according to this respondent.

All diplomats agreed that diplomacy is not a profession where one sees immediate results or quick wins. Successful diplomacy rests on hard work and patience: it takes time to build fruitful relationships. This realization invokes a deep sense of humility and also pragmatism. 
In the words of one diplomat: "You have to be humble, diplomacy does not deliver fast results." In the same vein, we found a shared acknowledgement of the complexity of both international and human relations. A diplomat must be credible and must enjoy the total confidence of the host government. In the words of one respondent, this means "[...] that they [the host government] can trust you and also that you speak with authority for your government". It also implies that diplomats must not promise something to the host country that their own country cannot do or deliver.

To conclude, emotional management appears to be a key factor for the effectiveness of a diplomat. One diplomat noted: "We had better be prepared to manage our emotions and represent our countries to the best of our abilities." We found that three emotional and social competencies recurred throughout the responses: emotional self-management, the ability to build meaningful relationships, and intercultural effectiveness. In the next chapter, we will provide some suggestions as to how to include our findings in future diplomatic training programs.

\section{Implications for Diplomatic Training}

Based on our literature review and the interviews we conducted, we argue that training can help diplomats strengthen their capacities for self-awareness, empathy and compassion. We acknowledge that some individuals may start out with stronger emotional, social and cultural competencies than others. As one interviewee said, "it comes easier for people who are this way, who are less emotional, who focus more on understanding and less on judging". Another diplomat noted that not everybody might have what it takes to be effective in sensitive, highly-charged international negotiations. While this holds true and needs to be factored in, research has shown that these competencies are not fixed, but that they can also be developed and strengthened in adulthood (Boyatzis, 2009).

Our core message is that it is vital for diplomats to realize the importance of emotional, social, and intercultural competencies for their work. Effective diplomats will continuously whether consciously or unconsciously - develop these competencies throughout their careers. As one diplomat pointed out: "I think one cannot teach this to a diplomat in a classroom. They need to get out and do it. And they need a good mentor who can guide them." Indeed, empirical evidence indicates that diplomats accumulate competencies throughout and through their different assignments (Megahed et al., 2012). Still, this might not be enough or, at the very least, this process can be supported by training. Experts arguing specifically for increased intercultural communication training for diplomats include Bolewski (2008) and Korshuk (2004).

We acknowledge the limits of training as a standalone exercise and argue for a holistic approach to training (for example, standalone sessions combined with a sustained commitment to on-the-job training, as well as support from diplomatic peers). Yet, based on our experience as practitioners as well as the body of research documenting the effectiveness of emotional and intercultural training, we strongly believe that standard diplomatic training for junior diplomats should include modules on emotional, social, and intercultural competencies. Such training may help sensitize young diplomats and provide them with tools to respond to difficult situations - which they are almost certain to encounter in their work - in a constructive manner. It will raise their awareness of the issues at stake and allow them to build their emotional, social and intercultural muscles to increase their professional effectiveness.

Another argument for incorporating emotional, social and cultural competencies into standard diplomatic training is the signal that this sends: that emotional, social, and intercultural competencies are issues that the organization cares about. This in itself is a 
powerful message. A foreign ministry might also consider establishing a mentoring system. This often happens naturally, i.e. a more senior colleague consciously taking a junior colleague under his or her wing, but it might be helpful to offer a platform and meeting opportunities for mentors and mentees.

In the following, we have organized our recommendations according to the analytical framework of Deardorff's pyramid model of intercultural competence. We have also been inspired by the work of Boyatzis and Goleman on emotional and social intelligence, which helped us both in analyzing our interviews and developing the recommendations below. Concretely, we suggest including the following competencies into diplomatic training:

\section{Competence 1. Self-Management}

Knowledge and comprehension: Self-awareness of character, emotions, motives, and desires; understanding of one's own beliefs, values, and experiences shaping one's worldview; understanding one's own strengths and weaknesses as a person and as a professional; self-regulation and self-management tactics.

Abilities: Self-reflection; self-regulation; learning from one's experiences; thinking clearly under pressure; managing stress in a constructive manner; staying composed in the most trying moments.

Attitudes: Modesty; belief in life-long learning and self-development; positive worldview; appreciative of feedback; sense of dignity and self-worth; self-motivation.

The ability to manage disruptive emotions and impulses and the ability to stay composed and think clearly in difficult situations are essential for the success of a diplomat. Those two traits were mentioned by the majority of the respondents. One respondent said:

It is too easy to give in to your instincts and do one of the two: fight or flight. The art of our job is not to give in to our urges. We have an obligation to think clearly in the most daring moments, and come up with a response that represents ourselves and our country in a most dignified way.

The senior diplomats also observed that sometimes the national, professional, and individual identities of diplomats can clash. The clash between a strong national narrative where a conflict has left deep wounds and an imprint on the national identity - and the professional identity of a diplomat can be profound. To successfully maneuver this balancing act, highly developed self-management skills are required. It will be critical for the diplomat to identify and analyze situations that might trigger them to move into a negative mode. Equally, awareness about emotional modes and responses needs to be established in order to change unproductive patterns and better respond to challenges.

\section{Competence 2. Building and Maintaining Relationships}

Knowledge and comprehension: Understanding of how one's behavior and feelings affect others; understanding the role of emotions in human interactions; knowing how to behave appropriately in different contexts (for example, social norms versus professional norms); being aware of useful communication techniques and effective conflict resolution strategies.

Abilities: Communicate clearly and persuasively; listen actively; practice empathy and appreciative inquiry; engage in negotiations with a positive attitude to achieve results. 
Attitudes: Respect towards people; trustworthiness; optimism; spirit of cooperation; patience; belief in win-win approaches to conflict resolution.

Trust is the backbone of resonant, long-standing relationships. Yet, trust is not a given: it needs to be earned and cultivated as our interview partners pointed out. Empathy has been highlighted the most among the traits relating to social competence. It was described as the ability to sense other's feelings and perspectives by one diplomat; another described it as showing an active interest in people's concerns. Empathy was also described as the ability to put oneself in the shoes of the other. Active listening has been mentioned as the most effective means both to gain empathy and understanding and demonstrate it. Rifkind (2014) notes that "empathy is like a muscle that needs training" (Rifkind \& Picco, 2014, p. 34). Empathy fosters understanding and trust; it thus represents a key competence for the successful work of a diplomat, as has been underlined by our interviewees.

\section{Competence 3. Intercultural Effectiveness}

Knowledge and comprehension: Deep understanding of the role of culture in shaping people's world views, attitudes and behaviors (including one's own); culture-specific information (beliefs, values, and behaviors of the cultural context one is operating in); sociolinguistic awareness.

Abilities: Observe, recognize and analyze cultural differences; adapt; build and maintain informal networks; manage ambivalence positively.

Attitudes: Appreciation of diversity; respecting other cultures; sensitivity; curiosity and openness; flexibility.

The importance of having a strong sense of curiosity and discovery has been highlighted as fundamental by the diplomats participating in this study. They suggested that effective diplomats seek out culture-specific information from a wide variety of sources to better understand the local context. In addition, they try to avoid generalizations and stereotypes. One of the diplomats uses a hobby as a way of building informal networks and meeting people outside the diplomatic community.

It is great to talk to diplomats, but we have an established way of looking at things. It is better to talk to people who have experienced the country from a different perspective. For example, I go hiking and meet all kinds of people, both local and international. Hiking gave me an exposure to parts of the country that I would have never seen otherwise.

Socio-linguistic awareness is another critical factor for understanding one's counterparts and the context. For example, in more collective cultures such as Azerbaijani culture, saving face is important. This is one of the reasons why locals tend to avoid using the word "No". Instead, they use more elaborate verbal and non-verbal clues to express their disapproval. One of the diplomats who had served in Azerbaijan observed:

If you do not get a response to your second meeting request, most likely this means "No." But foreigners are oblivious to such clues, because they are used to a straight "No."

This indicates that individuals from different cultural backgrounds use distinct sets of actions to express disapproval. An effective diplomat is aware of such differences and will be able to read the clues correctly. 


\section{Concluding Thoughts}

In this article, we have examined competencies that diplomats need to be effective in their work in the face of ambivalence and conflict. Diplomats can experience ambivalence for different reasons. For the purpose of this paper, we have focused on how diplomats cope with dissonance created by conflicts between their personal and professional identities, as well as by intercultural challenges. In doing so, we have tried to incorporate research findings from different disciplines, as there is a need to incorporate perspectives from other disciplines in intercultural competence work (Arasaratnam, 2014). We hope that this article has shed some light on how diplomats successfully handle ambivalence and how their experiences can be translated into competencies and incorporated into diplomatic training.

By conducting interviews with senior diplomats, we have come to the conclusion that selfmanagement, relationship building, and intercultural effectiveness are three core competencies that should be included in the learning objectives of diplomatic training programs. The next task will be to look more closely at possible tools and processes for training modules designed to support young diplomats in strengthening their emotional, social, and cultural fitness. Our research has also raised several questions that deserve further analysis: do personnel selection processes in foreign ministries take account of the above-mentioned competencies in order to predict job effectiveness; and how do diplomats perform the complex task of rising above a predominant national narrative shaped by an on-going conflict?

Respect, credibility, and professionalism form the basis of the resonant working relationships necessary between diplomats in order to foster dialogue at the bilateral and multilateral level. The core finding of this article is that emotions in diplomatic work need to be acknowledged. We argue that competencies such as self-management, building and maintaining relationships, and intercultural effectiveness need to be nurtured in order to support diplomats in managing the ambivalence they are set to experience in their work. Maya Angelou once said: "It is by observation that in the future they will not remember what you said, they will not remember what you did, but they will remember how you made them feel".

This is as true in everyday life as it is in the world of diplomacy. 


\section{References}

Abbey, E., \& Valsiner, J. (2004). Emergence of meanings through ambivalence. Forum Qualitative Sozialforschung, 6(1). Retrieved from http://www.qualitative-research.net/index.php/fas/article/view/515.

Abbey, E., \& Valsiner, J. (2005). The making of somebody else: diagnostic labels, educational practices, and meaning-making. European Journal of School Psychology, $3(1), 83-99$.

Albrecht, K. (2006). Social intelligence: The new science of success. San Francisco: JosseyBass.

Arasaratnam, L. A. (2014). Ten years of research in intercultural communication competence (2003 - 2013): A retrospective. The Journal of Intercultural Communication, Issue 35. Retrieved from http://www.immi.se/intercultural/nr35/arasaratnam.html.

Armitage, C. J., \& Conner, M. (2000). Social cognition models and health behaviour: A structured review. Psychology \& Health, 15(2), 173-189.

http://dx.doi.org/10.1080/08870440008400299

Barna, L. M. (2009). The stress dynamic and its intersection with intercultural communication competence. In M. A. Moodian (Ed.), Contemporary leadership and intercultural competence. Exploring the cross-cultural dynamics within organizations (pp. 139-144). Thousand Oaks, California: Sage. http://dx.doi.org/10.4135/9781452274942.n11

Bar-On, R. (1997). Bar-On emotional quotient inventory: Technical manual. Toronto: MultiHealth Systems.

Barry, B., \& Friedman, R. (1998). Bargainer characteristics in distributive and integrative negotiation. Journal of Personality and Social Psychology, 74(2), 345-359. http://dx.doi.org/10.1037/0022-3514.74.2.345

Bazerman, M. H., Curhan, J. R., \& Moore, D. A. (2000). The death and rebirth of the social psychology of negotiation. In G. J. O. Fletcher \& M. S. Clark (Eds.), Blackwell Handbook of Social Psychology: Interpersonal processes (pp. 196-228). Oxford, England: Blackwell Publishers.

Bennett-Goleman, T. (2013). Mind Whispering: A New Map to Freedom from Self-Defeating Emotional Habits. New York: HarperOne.

Bolewski, W. (2008). Diplomatic processes and cultural variations: The relevance of culture in diplomacy. The Whitehead Journal of Diplomacy and International Relations, Winter/Spring 2008, 145-160.

Boyatzis, R. E. (2008). Leadership development from a complexity perspective. Consulting Psychology Journal, 60(4), 298-313.

http://dx.doi.org/10.1037/1065-9293.60.4.298

Boyatzis, R. E. (2009). Competencies as a behavioral approach to emotional intelligence. Journal of Management Development, 28 (9), 749-770. http://dx.doi.org/10.1108/02621710910987647

Boyatzis, R. E. (2011). When pulling to the negative emotional attractor is too much or not enough to inspire and sustain outstanding leadership. Manuscript, November 2011.

British Psychological Society (2010). Code of Human Research Ethics. Retrieved from http://www.bps.org.uk/sites/default/files/documents/code of human_research 
Deardorff, D. (2009). Implementing intercultural competence assessment. In D. Deardorff (Ed.), The SAGE Handbook for Intercultural Competence (pp. 477-491). Thousand Oaks, California: SAGE Publications.

Eagly, A. H., \& Chaiken, S. (1993). The psychology of attitudes. Fort Worth, Texas: Harcourt.

Earley, P. C., \& Ang, S. (2003). Cultural intelligence: An analysis of individual interactions across cultures. Palo Alto, California: Stanford University Press.

Elenkov, D., \& Pimentel, R. (2008). Social intelligence, emotional intelligence, and cultural intelligence. An integrative perspective. In S. Ang, \& S. Van Dyne (Eds.), Handbook of cultural intelligence: Theory, measurements, and applications (pp. 289-305). London: M.E. Sharpe.

Emmerling, R. J., \& Boyatzis, R. E. (2012). Emotional and social intelligence competencies: cross cultural implications. Cross Cultural Management: An International Journal, 19(1), 4-18.

http://dx.doi.org/10.1108/13527601211195619

http://dx.doi.org/10.1108/13527601211195592

Eysenck, H., \& Eysenck. M. (1995). Mindwatching. Why we behave the way we do. London: Prion.

Froese, U. (2013). Quiet, not silent. Interview with Knut Vollebaek, High Commissioner on National Minorities. Security Community, The OSCE Magazine, 1(1), 34-38.

Fulmer, I. S., \& Barry, B. (2004). The smart negotiator: cognitive ability and emotional intelligence in negotiation. International Journal of Conflict Management, 15(3), 245-

272. http://dx.doi.org/10.1108/eb022914

Goleman, D. (1995). Emotional intelligence. Why it can matter more than IQ. New York: Bantam Dell.

Goleman, D. (2006). Social intelligence. The revolutionary new science of human relationships. New York: Bantam Dell.

Hall, E. T. (1976). Beyond culture. New York: Anchor Books.

Hofstede, G. (2004). Diplomats as cultural bridge-builders. In H. Slavik (Ed.), Intercultural communication and diplomacy (pp. 25-38). Malta, Geneva: DiploFoundation.

Judge, T. A., \& Piccolo, R. F. (2004).Transformational and transactional leadership: A metaanalytic test of their relative validity. Journal of Applied Psychology, 89(5), 755-768. http://dx.doi.org/10.1037/0021-9010.89.5.755

Kappeler, D. (2004). The birth and evolution of a diplomatic culture. In H. Slavik (Ed.), Intercultural communication and diplomacy (pp. 353-359). Malta, Geneva:

DiploFoundation.

Kastner, H. (2014). Wut. Plädoyer für ein verpöntes Gefühl. Wien: Kremayr \& Scheriau.

Korshuk, A. (2004). On intercultural training of diplomats. In H. Slavik (Ed.), Intercultural communication and diplomacy (pp. 405-415). Malta, Geneva: DiploFoundation.

Lavine, H., Huff, J. W., Wagner, S. H., \& Sweaney, C. (1998). The moderating influence of attitude strength on the susceptibility to context effects in attitude surveys. Journal of Personality and Social Psychology, 75(2), 359-373.

http://dx.doi.org/10.1037/0022-3514.75.2.359

LePine, J. A., Colquitt, J. A., \& Erez, A. (2000). Adaptability to changing task contexts: Effects of general cognitive ability, conscientiousness, and openness to experience. Personnel Psychology, 53(3), 563-593.

http://dx.doi.org/10.1111/j.1744-6570.2000.tb00214.x 
Maalouf, A. (2000). In the name of identity. Violence and the need to belong. Translated from the French by Barbara Bray. New York: Arcace Publishing.

Märtsin, M., \& Mahmoud, H. W. (2012).Never "at-Home"? In J. Valsiner (Ed.).The Oxford Handbook of Culture and Psychology (pp.710-729). New York: Oxford University Press.

Mastracci, Sharon H., Newman, Meredith A., \& Mary E. Guy (2010). Emotional labor: Why and how to teach it. Journal of Public Affairs Education, 16 (2), 123-14.

Mayer, J. D., \& Salovey, P. (1997). What is emotional intelligence? In P. Salovey \& D. Sluyter (Eds.), Emotional development and emotional intelligence: educational implications (pp. 3-31). New York: Basic Books.

McClelland, D. C. (1973). Testing for competence rather than for "intelligence". American Psychologist, 28(1), 1-14. http://dx.doi.org/10.1037/h0034092

Megahed, N., Van der Heijden, B. I. J. M., Shaker, M., \&Wahba, K. M. (2012). A framework for developing a multiple-jobs competency model for diplomats. International Journal of Business and Science, 3(24), 42-55.

Pasquali, G. (2014). The role of diplomatic culture in international disputes. Peace Review, 26(2), 273-280. http://dx.doi.org/10.1080/10402659.2014.907010

Rana, K. S. (2004). Diplomatic culture and its domestic context. In H. Slavic (Ed.), Intercultural communication and diplomacy (pp. 391-290), Malta and Geneva: DiploFoundation.

Rifkind, G., \& Picco, G. (2014). The fog of peace. The human face of conflict resolution. London, New York: I.B. Tauris.

Rockstuhl, T., Seiler, S., Ang, S., Van Dyne, L., \&Annen, H. (2011). Beyond general intelligence (IQ) and emotional intelligence (EQ): The role of cultural intelligence (CQ) on cross-border leadership effectiveness in a globalized world. Journal of Social Issues, 67(4), 825-840. http://dx.doi.org/10.1111/j.1540-4560.2011.01730.x

Rozen, L. (2014, October 7). Former US diplomat fosters US-Iran ties behind the scenes. Al-Monitor. Retrieved from http://www.al-monitor.com/pulse/originals

Rubin J., \& Brown, B. (1975). The social psychology of bargaining and negotiation, New York: Academy Press.

Russell, W. E. (2004). "Control Yourself, Sir!". A call for research into emotion cultures in diplomacy. In H. Slavik (Ed.), Intercultural communication and diplomacy (pp. 391402). Malta, Geneva: DiploFoundation.

Sharp, P. (1997). Who needs diplomats? The problems of diplomatic representation. International Journal, 52(4), 609-634. http://dx.doi.org/10.2307/40203245

Sirin, C. V., Villalobos, J. D., \& Geva, N. (2011). Political information and emotions in ethnic conflict interventions. International Journal of Conflict Management, 22(1), 35-59. http://dx.doi.org/10.1108/10444061111103616

Spitzberg, B. H., \& Changnon, G. (2009). Conceptualizing intercultural competence. In Deardorff, D. (Ed.), The SAGE Handbook of Intercultural Competence (pp. 2-52). Thousand Oaks, California: Sage.

Tagliavini, H. (2013). Women in peacekeeping: how to survive and succeed. Security Community, The OSCE Magazine, 1(1), 26-29.

Thompson, M. M., \& Zanna, M. P. (1995). The conflicted individual: Personality-based and domain-specific antecedents of ambivalent social attitudes. Journal of Personality, 63(2), 259-288. http://dx.doi.org/10.1111/j.1467-6494.1995.tb00810.x 
Thorndike, E. L. (1920). Intelligence and its uses. Harper's Monthly Magazine, Vol. 140, 227-235.

Van Dyne, L., Ang, S., \& Koh, C. K. S. (2009). Cultural intelligence: Measurement and scale development. In M. A. Moodian (Ed.), Contemporary Leadership and Intercultural Competence: Exploring the Cross-Cultural Dynamics within Organizations (pp. 233254). Thousand Oaks, California: Sage. http://dx.doi.org/10.4135/9781452274942.n18

Van Dyne, L., Ang, S., \& Livermore, D. (2010). Cultural intelligence: A pathway for leading in a rapidly globalizing world. In K. M. Hannum, B. McFeeters, \& L. Booysen (Eds.), Leading across differences (pp. 131-138). San Francisco, California: Pfeiffer. 


\section{About the Authors}

Shamsiyya Mustafayeva has fifteen years of leadership and management experience. She holds a master's degree in Teaching Methodology from the Azerbaijan University of Languages and a dual master's degree in Public Administration and International Relations from the Maxwell School of Syracuse University. She served as Associate Vice-Rector at ADA University until April 2014. Currently Ms. Mustafayeva is working as an independent management development consultant and finds consultancy work very fulfilling.

E-mail: mustafayeva.shams@gmail.com

Astrid Schnitzer-Skjønsberg is an international development consultant based in Oslo. She holds master's degrees from the Vienna University of Economics and Business Administration (International Business and Chinese) and Columbia University (International Affairs). She has been involved in intercultural communication training for more than a decade and has worked in diplomacy both at the bilateral and multilateral level.

E-mail: astrid.schnitzer@gmail.com 